\title{
Da Necessidade de Corroboração Probatória para a Reconstrução de Sentidos em Diálogos Obtidos por Interceptações Telefônicas
}

\author{
The Need for Evidential Corroboration for the Reconstruction of \\ Meanings on Dialogues Obtained by Telephonic Interceptions
}

\section{Vitor de Paula Ramos ${ }^{1}$}

\author{
Universitat de Girona, España \\ vitordepaularamos@hotmail.com \\ http://lattes.cnpq.br/1139010003942410 \\ http://orcid.org/0000-0001-6811-2891
}

\begin{abstract}
REsUMO: O presente estudo pretende abordar a questão da reconstrução de sentidos de diálogos obtidos a partir de interceptações telefônicas. Assim, na primeira parte apresenta conceitos da semiótica e da epistemologia para, na segunda parte, aplica-los a um caso real. Tudo a fim de responder a dois questionamentos: (i) a reconstrução de sentidos de textos, palavras ou frases pode se dar de maneira independente do contexto de sua utilização?; (ii) como é possível conhecer o contexto de uma comunicação? A metodologia utilizada é a revisão bibliográfica de escritos da semiótica e da epistemologia, utilizando-se caso real para ilustrar.

Palavras-chave: Prova; Gravações; Epistemologia aplicada ao processo penal; Semiótica aplicada ao processo penal; Peso da prova combinada.
\end{abstract}

1 Doutor em Direito, Economia e Empresa pela Universidade de Girona (Espanha), cum laude. Mestre e Doutor em Direito pela Universidade Federal do Rio Grande do Sul (UFRGS), onde se graduou com láurea acadêmica. Professor do Master em Razonamiento Probatorio da Universidade de Girona (Espanha) e nos cursos de pós-graduação lato sensu em Processo Civil da PUCRS e da Uniritter. Professor convidado em diversos cursos de Processo Civil e Direito Probatório, no Brasil e no Exterior. Membro efetivo do Instituto Brasileiro de Direito Processual (IBDP). Membro do Conselho Assessor da Revista Internacional de Direito Probatório Quaestio Facti. Coordenador da Coleção Raciocínio Probatório, publicada na Editora JusPodivm. Autor de livros e artigos publicados no Brasil e no exterior, além de traduções jurídicas. Advogado atuante no RS e em SP, sócio de Silveiro Advogados. 
ABSTRACT: The present study is aimed to deal with the reconstruction of meanings of intercepted dialogues. Being so, on the first part, it presents concepts of semiotics and epistemology; on the second part, those concepts are applied to a real case. All of that aiming to answer two questions: (i) is the reconstruction of meanings of texts, words or sentences independent of the context of its use? (ii) how is it possible to get to know the context of the communication? The methodology used is the analysis of bibliography on semiotics and epistemology, using a real case as example.

KEYWORDS: Evidence; Recordings; Epistemology applied to criminal procedure; Semiotics applied to criminal procedure; Weight of combined evidence.

SuMÁRIo: Introdução. 1. As palavras, frases e textos como símbolos. 1.1 A semiótica e os símbolos. 1.2. Lições da epistemologia: a necessidade de maior completude do material probatório. 20 problema e formas de solução. A necessidade da prova do contexto para a interpretação da linguagem. 2.10 problema. 2.2. A indexicalidade do som, o simbolismo da linguagem e a necessidade de busca de sentidos possíveis. 2.3. A busca pela corroboração das hipóteses e o peso da combinação de provas. Considerações finais. Bibliografia.

\section{INTRODUÇÃO}

O uso da linguagem está em toda a interpretação e aplicação do Direito. Curiosamente, entretanto, a teoria geral do direito preocupou-se muito nas últimas décadas em desenvolver teorias e doutrinas a respeito da interpretação da linguagem no plano da aplicação do direito (isto é, interpretação dos textos normativos), mas pouco ou quase nada ${ }^{2}$ a respeito da reconstrução de sentidos relacionados a provas que envolvam a linguagem ${ }^{3}$.

2 Constitui exceção a essa afirmação o artigo de FANTINI, Daniel Fabio. "Interceptação Telefônica e Linguagem”. Revista Brasileira de Ciências Policiais, v. 3, n. 1, p. 11-25, jan/jun 2012, em que o autor trabalha com as ideias de Searle para abordar os aspectos relacionados aos atos de fala indiretos nos diálogos obtidos mediante interceptações telefônicas.

3 As referências à semiótica feitas no presente artigo possuem escopo muito menor do que aquele conferido por parte da doutrina, por influência de 
Assim, apesar de reconhecida a polissemia das palavras, a independência de sentidos e a necessidade de escolha entre sentidos possíveis por parte do intérprete no campo da interpretação de textos legais, pouca atenção foi dada para esses mesmos atributos quando tais interpretações dizem respeito à atribuição de significados à linguagem utilizada em diálogos obtidos a partir de interceptação de comunicações telefônicas.

Duas são as perguntas fundamentais: (i) a reconstrução de sentidos de textos, palavras ou frases pode se dar de maneira independente do contexto de sua utilização?; (ii) como é possível conhecer o contexto de uma comunicação?

O presente estudo pretende responder tais questionamentos partindo de conhecimentos da semiótica, para demonstrar que a linguagem, como conjunto de símbolos que é, possui atribuição de significados arbitrária, que dependem do contexto da comunicação e de hábitos coletivos

CORDERO, Franco. Procedura Penale. 9ª . Ed. Milão: Giuffrè, 2012, p. 574. O autor refere a uma aplicação geral da semiótica ao campo probatório, referindo-se ao que chama de "semiótica das provas"; para o autor, a questão centra-se em que é "fenômeno atípico e estatisticamente minúsculo a ciência [conhecimento] direta", de modo que, fazendo referência à teoria carneluttiana dos "equivalentes sensíveis" (CARNELUTTI, Francesco. La Prova Civile. 2a. ed. Roma: Edizioni dell'Ateneo, 1947, p. 122), sustenta que as provas seriam "signos do fato a ser conhecido". No mesmo sentido, adotando a ideia de CORDERO, LOPES JR., Aury. Direito Processual Penal. 17ª Ed. São Paulo: Saraiva Educação, 2020, p. 557. MORAES, Ana Luísa Zago de. "Prova Penal: Da Semiótica À Importância Da Cadeia De Custódia”. Revista Brasileira de Ciências Criminais. Vol. 132, p. 117-138, 2017. Não me parece a melhor solução, todavia, reduzir todo o campo da prova à semiótica. Afinal, como os próprios semiólogos se referem, a semiótica não se preocupa em saber "se o unicórnio existe ou não (...): ao passo que é importante saber como, em um certo contexto, a forma significante 'unicórnio' recebe um determinado significado em base a um sistema de convenções linguísticas” (ECO, Umberto. La Struttura Assente. Introduzione alla Ricerca Semiologica. Milano: Ed. Bompiani, 1968, p. 34). O papel de preocupar-se com a busca do que realmente ocorreu, com a qualidade das provas e dos raciocínios formulados, é, na minha opinião, da epistemologia, e não da semiótica. Minha referência à semiótica no presente estudo, portanto, é bastante mais modesta: pretendo socorrer-me dessa justamente no sentido proposto por ECO, isto é, para reconhecer que a linguagem, esta sim, possui atribuição de significados arbitrária (na medida em que os símbolos, como será visto, não possuem conexão causal com a natureza, mas sim com convenções), de modo que a mera existência de símbolos (como, por exemplo, a palavra "unicórnio") deve, necessariamente, passar por um processo de reconstrução de sentidos para que se possa reconstruir o conteúdo, por exemplo, de um diálogo. 
de referência. Assim, sem provas robustas a respeito dos contextos e hábitos envolvidos em uma comunicação, de forma clara e corroborada, qualquer tentativa de atribuição de significados pode ser, também dentro de um processo, bastante perigosa.

\section{As palavras, frases e textos como símbolos}

\subsection{A SEMIÓtica e os Símbolos}

A semiótica é o campo do conhecimento que se preocupa com o estudo dos signos, "em todas as suas formas de manifestações, (...), normais ou patológicos, linguísticos e não linguísticos, pessoais ou sociais”" Há muita discussão a respeito do significado de um signo (debate esse que refoge completamente ao escopo do presente trabalho), mas de maneira direta e concisa pode-se dizer que se trata de "um objeto que "está por outro [stands for another] para alguma mente" , "uma expressão que

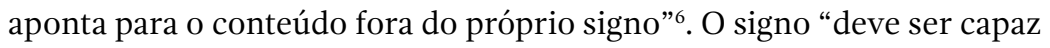
de estar conectado (...) a outro signo do mesmo objeto, ou ao próprio objeto"7. Isso é, a uma ideia ou diretamente a um objeto.

A relação dos signos com os objetos ou com as ideias, entretanto, nem sempre é igual. De acordo com Peirce, os signos podem ser divididos em três categorias, a saber, índices (indexes), ícones ou símbolos ${ }^{8}$.

4 MORRIS, Signification and Significance. A Study of the Relations of Signs and Values. Cambridge-Massachusetts, The MIT Press, 1964, p. 1.

5 PEIRCE, Charles. "On the nature of Signs". [1873]. In: HOOPES, James (org.). Peirce on Signs. Chapel Hill e Londres: The University of Carolina Pressa, 1991, p. 313. Como adverte NÖTH, Winfried. Handbook of Semiotics. Bloomington \& Indianapolis, 1990, p. 79, muitas foram as definições a respeito de signos. Adoto aqui a nomenclatura de PEIRCE, que é perfeitamente adequada para o escopo do presente trabalho.

6 HJELMSLEV, Louis. Prologomena to a Theory of Language. Trad. Fracis Whitfield. Londres: The University of Wiscosin Press, 1969, p. 45.

7 PEIRCE, Charles. "Some Consequences of Four Incapacities. [1868]. In: HOUSER, Nathan; KLOESEL, Christian (orgs.). The Essencial Peirce. Vol. 1. Bloomington: Indiana University Press, 1992, p. 40.

8 PEIRCE, Charles. Sign. [1901]. In: HOOPES, James (org.). Peirce on Signs. Chapel Hill e Londres: The University of Carolina Press, 1991, p. 519. 
Os índices são aqueles que possuem uma relação causal automática com a realidade, variando de acordo com essa. É o caso, por exemplo, de uma radiografia, cujo resultado varia em função de o osso estar ou não quebrado, e de uma fotografia, em que, de acordo com o que se apresenta diante da câmera, o resultado final varia (uma pessoa sai de olho fechado ou de olho aberto na fotografia, a depender de como estava no momento em que a fotografia foi tirada).

Os ícones, de seu turno, possuem uma relação de semelhança com a ideia ou o objeto, não dependendo diretamente da realidade e nem variando com ela. Uma pessoa que faz um retrato pode desenhar a outra pessoa sorrindo, ainda que ela esteja posando séria, sem sorrir ${ }^{9}$. Uma pessoa pode desenhar um unicórnio, ainda que unicórnios não existam.

Os símbolos, por fim, não possuem relações causais ou automáticas com a realidade (o "mundo lá fora"), mas sim com convenções que são previamente estabelecidas. É o caso de uma placa de "sentido proibido"10: na Itália, tal indicação é representada por um círculo vermelho com um retângulo branco na horizontal colocado no centro. Se tal placa fosse utilizada no Brasil não teria sentido algum para os brasileiros, visto que a mesma indicação, aqui, é representada por uma seta preta cortada por um traço vermelho diagonal.

Um diálogo gravado, portanto, possui caráter de índice e de símbolo. O primeiro porque a gravação varia de acordo com os sons que ocorreram na realidade: se alguém fala mais alto, a gravação regista um som mais alto, se alguém nada diz, a gravação regista o silêncio. E de símbolo porque as palavras, expressões e frases são determinadas de acordo com convenções previamente estabelecidas.

A questão central demonstrada pela semiótica em relação aos símbolos é que esses possuem um sentido ou outro somente em determinada sociedade, em determinado grupo, em determinado contexto temporal

9 Usando o exemplo de Mona Lisa e da Sra. Giocondo, ECO, Umberto. La Struttura Assente. Introduzione alla Ricerca Semiologica. Milano: Ed. Bompiani, 1968, p. 108.

10 ECO, Umberto. La Struttura Assente. Introduzione alla Ricerca Semiologica. Milano: Ed. Bompiani, 1968, p. 108. 
e cultural. Afinal, a ligação entre o significante e o significado é arbitrária ${ }^{11}$ - depende justamente de convenções previamente estabelecidas.

Um mesmo signo pode carregar, portanto, diversos sentidos ${ }^{12}$. A palavra eco, para um físico, significa o fenômeno de um som que bate em um anteparo e retorna; para um piloto de avião, a palavra eco significa a letra e. Para um médico, a palavra eco é a versão reduzida da palavra ecografia, de modo que quando um gastroenterologista comunica a um colega que solicitou uma eco abdominal esse não pensará se tratar de um pedido pela letra $e$ ou de um pedido para que o paciente emita um som diante de um anteparo.

O contexto da comunicação pode determinar, ademais, a utilização das palavras e frases em sentidos denotativos ou conotativos. Grosseiramente, pode-se dizer que os sentidos denotativos são os literais, e os conotativos são os sentidos figurados. Assim, quando alguém diz que outra pessoa é grande, em sentido literal estará dizendo, por exemplo, que se trata de alguém alto ("você viu o filho de Fulano recentemente? Nossa, ele cresceu muito rápido, está muito grande!"); ao passo que, em sentido figurado, poderá estar dizendo que se trata de uma pessoa com enorme importância ("Fulano é um grande do processo penal").

Apesar da pluralidade de sentidos denotativos e conotativos que uma palavra pode possuir, há, em um contexto e em um local específico, sentidos mínimos em que uma palavra ou expressão vêm utilizados.

A língua, como já mencionado, assim como qualquer outro sistema de símbolos, parte de hábitos coletivos, ou mesmo de convenções ${ }^{13}$, em uma relação de dupla influência: assim como a língua afeta os hábitos coletivos de atribuição de sentidos aos símbolos, também os hábitos coletivos

11 ECO, Umberto. La Struttura Assente. Introduzione alla Ricerca Semiologica. Milano: Ed. Bompiani, 1968, p. 35. No mesmo sentido, abordando a linguagem, SAUSSURE, Ferdinand de. Cours de Linguistique Générale. [1915]. 3a. ed. Payot: Paris, 1931, p. 75.

12 Conforme MORRIS, Charles. Signification and Significance. A Study of the Relations of Signs and Values. Cambridge-Massachusetts, The MIT Press, 1964, p. 3, "signos (...) admitidos como tendo significação diferem bastante no tipo de significação que possuem”.

13 SAUSSURE, Ferdinand de. Cours de Linguistique Générale. [1915]. 3a. ed. Payot: Paris, 1931, p. 75-76; ECO, Umberto. La Struttura Assente. Introduzione alla Ricerca Semiologica. Milano: Ed. Bompiani, 1968, p. 34. 
afetam a língua, que vai se alterando com a passagem do tempo. Daí que os símbolos linguísticos sejam, por um lado, imutáveis - na medida em que um só indivíduo não pode alterar os hábitos coletivos -, e, por outro lado, mutáveis ${ }^{14}$ - na medida que, com o passar do tempo, diversas podem ser as alterações dos hábitos coletivos que influenciarão a atribuição de sentidos.

A relação entre os sentidos mínimos e a polissemia das palavras e símbolos em geral podem ser vistas com o exemplo da palavra "cachorro", que poderia denotar tanto um dogue alemão quanto um poodle (isso sem falar em diversos sentidos conotativos). Por outro lado, "cachorro" não pode ser interpretado como o sinônimo de uma hortênsia, ou de um abajur. E justamente aí aparecem os sentidos mínimos ${ }^{15}$.

Apesar de os signos poderem ser vistos como "transportadores de sentidos" ${ }^{16}$, portanto, a significação é um processo ${ }^{17}$, que envolve, naturalmente, o signo em si (e, naturalmente, quem ou o que o criou), mas também a interpretação. O que é importante notar desde logo é que a semiótica, nesse sentido, preocupa-se em entender como "a forma significante 'unicórnio' recebe um determinado significado com base em um sistema de convenções linguísticas"18; e não em saber "se o unicórnio existe ou não (...)"19.

\subsection{LIÇÕES DA EPISTEMOLOGIA: A NECESSIDADE DE MAIOR COMPLETUDE DO MATERIAL PROBATÓRIO}

Se a semiótica não se preocupa com saber se o que é descrito pela linguagem existe ou não, é preciso recorrer-se, em um processo que se

14 SAUSSURE, Ferdinand de. Cours de Linguistique Générale. [1915]. 3a. ed. Payot: Paris, 1931, p. 82.

15 ÁVILA, Humberto. Teoria dos princípios: da definição à aplicação dos princípios jurídicos. 18a. Ed. São Paulo: Malheiros Editores, 2018, p. 54.

16 HJELMSLEV, Louis. Prologomena to a Theory of Language. Trad. Fracis Whitfield. Londres: The University of Wiscosin Press, 1969, p. 44.

17 ECO, Umberto. La Struttura Assente. Introduzione alla Ricerca Semiologica. Milano: Ed. Bompiani, p. 31.

18 ECO, Umberto. La Struttura Assente. Introduzione alla Ricerca Semiologica. Milano: Ed. Bompiani, p. 34.

19 ECO, Umberto. La Struttura Assente. Introduzione alla Ricerca Semiologica. Milano: Ed. Bompiani, p. 34. 
baseia em conhecer o que realmente ocorreu para atribuir consequências jurídicas, para algum outro ramo do conhecimento que tenha tal preocupação. Tal ramo é justamente a epistemologia, o ramo da filosofia que estuda a obtenção de conhecimento ${ }^{20}$. A epistemologia, naturalmente, não substitui a teoria jurídica, mas serve para buscar melhorar nossas "regras ou, melhor, linhas mestras para a condução de uma apuração [inquiry]"21, reconhecendo quais ambientes "apoiam [are supportive of] e quais são hostis em relação à apuração bem-sucedida" ${ }^{22}$.

Uma dessas questões é saber como, dentro e fora de um processo, ocorre o aumento do grau de justificação de uma determinada hipótese. Como é possível dizer que a afirmação "cigarro causa câncer" está mais justificada epistemicamente do que "extrato de casca de laranja mata o coronavírus"? E a epistemologia sugere três eixos centrais para tal aumento de corroboração. O primeiro é a prova direta da própria hipótese [suportiveness]; o segundo, quão seguro é o "encaixe" da prova em questão com o que já sabemos previamente, independentemente da hipótese [independent security ${ }^{23}$. E em terceiro lugar, a quantidade de provas relevantes incluídas na busca, a chamada comprehensiveness ${ }^{24}$. E os três eixos estão absolutamente interligados ${ }^{25}$.

20 Sobre a epistemologia aplicada ao processo penal vide BADARÓ, Gustavo. Epistemologia Judiciária e Prova Penal. São Paulo: RT, 2019, esp. pp. 131 e ss.

21 HAACK, Susan. Manifesto of a Passionate Moderate. Chicago: University of Chicago Press, 1993, p. 130-131. HAACK, Susan. Manifesto of a Passionate Moderate. Chicago: University of Chicago Press, 1993, p. 130-131. HAACK, Susan. Evidence and Inquiry. 2a. Ed. New York: Prometheus Books, 2009, p. 132.

${ }^{24}$ HAACK, Susan. Evidence and Inquiry. 2a. Ed. New York: Prometheus Books, 2009, p. 132.

25 O funcionamento, segundo HAACK, Susan. Evidence and Inquiry. 2a. Ed. New York: Prometheus Books, 2009, p. 129 e ss., pode ser comparado a um jogo de palavras cruzadas. As entradas no jogo devem não só "satisfazer" as dicas dadas, mas também as palavras que se entrecruzam. Se, preenchendo a cruzadinha, imagina-se que no espaço de quatro letras a palavra seja "amor" (cruzando-se com a palavra "omelete", tendo o " $\mathrm{m}$ " em comum), será necessário verificar se a entrada, independentemente de qualquer coisa, "satisfaz" a dica. Se essa for, por exemplo, "tipo de pneu utilizado em automobilismo", não haverá suporte para definir que a palavra é, de fato, "amor". Entretanto, não dependerá somente disso, mas também da correção da entrada da 
A comprehensiveness ${ }^{26}$, que auxiliará no presente ensaio, diz respeito à completude tendencial do material probatório. Isso quer dizer que qualquer apuração dos fatos que realmente pretenda apurar os fatos deve ter o fim de incluir, tendencialmente ${ }^{27}$, todas as provas relevantes ${ }^{28}$. Isso não quer dizer, naturalmente, que as provas devam ser obtidas a qualquer custo, desrespeitando as regras do jogo, pois a apuração dos fatos, apesar de ser o fim principal do procedimento probatório, não é o único fim desse e nem do processo; quer, isto sim, dizer que, aumentando a comprehensiveness, aumenta-se a qualidade da apuração e do grau de justificação: "um conjunto probatório maior (...) é geralmente um indicador melhor do truth-value de uma hipótese do que um menor". ${ }^{29}$

A pandemia do coronavírus, em 2020, pode dar um bom exemplo: diante da pandemia, os cientistas passaram a formular e a testar hipóteses a respeito do comportamento do vírus, da sua estrutura, bem como de como criar substâncias e/ou formas de exterminá-lo. Iniciou-se, assim, uma apuração, feita por diversas pessoas, em diversos lugares do mundo. Tal apuração não começou, entretanto, do zero. Afinal, já existiam conhecimentos previamente confirmados ao longo do tempo por diversos outros experimentos e testes, por exemplo, a respeito da gravidade, da osmose, da estrutura da proteína, da estrutura de determinadas substâncias etc.

Se um cientista cria, portanto, a hipótese de que o coronavírus possui uma camada de gordura que envolve a sua cápsula, utilizará os conhecimentos disponíveis na data de hoje, para predizer que o detergente será capaz de destruir tal camada. O evento será submetido a

palavra "omelete". Ou seja, p. "omelete” dependerá de "amor" e vice-versa, e cada uma dessas dependerá de suas dicas. Quanto mais essas se "complementarem", mais justificado estará o preenchimento.

26 HAACK, Susan. Evidence and Inquiry. 2a. Ed. New York: Prometheus Books, 2009, p. 132.

27 Digo "tendencialmente" porque muitas das provas relevantes podem ser desconhecidas ou inacessíveis, mas as provas relevantes disponíveis devem, tendencialmente, fazer parte da apuração, a fim de que essa seja o melhor possível.

28 HAACK, Susan. Manifesto of a Passionate Moderate. Chicago: University of Chicago Press, 1993, p. 68.

29 GOLDMAN, Alvin I. Knowledge in a Social World. Oxford: Oxford University Press, 1999, p. 292. 
experimentos, buscando isolar tal fator. Se a predição se confirmar, a hipótese terá recebido um grau de suporte. Se não se confirmar, será necessário construir outras hipóteses. Será que essa camada de gordura do coronavírus possui alguma proteção ou algum tipo de resistência ao detergente? Será que a camada não é de gordura? Será que estávamos certos em pensar que o detergente é eficiente para destruir a gordura? ${ }^{30}$

O que a ciência faz, então, é contar com diversas pessoas, em diversos lugares, fazendo hipóteses a respeito de determinados fatos, buscando explicações e, posteriormente, confirmações a respeito do que acontece(u) no mundo lá fora - algo que leva tempo. Quanto mais pesquisas forem estabelecidas ao longo do tempo, maior será o número de provas relevantes, aumentando a comprehensiveness e, também, a qualidade da busca epistêmica. Em abril de 2020, o uso da medicação X para o tratamento do coronavírus ainda não passara por testes; encontrava-se recém na etapa das hipóteses e das testagens iniciais ${ }^{31}$.

A aplicabilidade disso para o direito - e para o tema do presente estudo - é enorme. Quando uma prova isolada aponta em algum sentido, a apuração envolverá não somente a utilização de conhecimentos prévios,

30 Veja-se que a segurança independente e a prova direta do caso podem afetar-se reciprocamente. A hipótese do detergente destruindo a gordura afetará o grau de confirmação das hipóteses do experimento sobre a existência de gordura na cápsula do coronavírus, mas poderá acabar determinado uma corroboração a respeito dos limites do detergente; antes se acreditava que o detergente era efetivo contra os tipos de gordura A, B e C, mas tal pesquisa levantou suspeitas de que pode ser que não seja dessa forma. Tais conhecimentos sobre o coronavírus estavam, em abril de 2020, recém sendo hipotizados, ao contrário, por exemplo, da associação do cigarro com câncer de pulmão, hipnotizada muitos anos atrás, já se encontrava em abril de 2020 testada durante mais de 30 anos, em diversos tipos de estudos, em diversos lugares do mundo e com diversos sujeitos.

Em condições normais, aliás, os medicamentos passam por diversas etapas de testes antes de chegarem ao mercado, a fim de que seja aumentada a corroboração sobre a segurança de sua utilização. No Brasil, primeiro são feitos testes em animais (estudos pré-clínicos); após, iniciam-se os estudos clínicos, divididos em quatro fases (a primeira com vinte a cem indivíduos, a segunda com cem a trezentos e a terceira com mil a três mil). Para poder ser comercializado, o medicamento deve passar nas três primeiras, ficando, em seguida, na quarta fase, em período de farmacovigilância. As etapas descritas a seguir estão disponíveis, p. 16 e ss. [www.abto.org.br/abtov03/Upload/file/ manual_do_transplantado/Farmacovigilancia.pdf]. Acesso em 16.04.2020. 
que podem ser demonstrados equivocados, mas também podem ser falseados totalmente pela produção de outras provas.

$\mathrm{O}$ ponto pode ficar claro a partir de um exemplo. Imagine-se uma ligação interceptada que inicie com uma pessoa atendendo e a outra simplesmente dizendo: "vou te matar", desligando em seguida. Poder-se-ia concluir desde logo, e sem qualquer contexto, tratar-se de uma ameaça? Como a hipótese da ameaça não poderia ser descartada desde logo, essa teria que ser apurada, mediante a produção de outras provas.

Imagine-se, então, que, mediante a produção de outras provas, descobre-se o seguinte contexto: o homem que efetuou a ligação ficara sabendo que a sua ex-namorada, depois de 6 meses da separação, assumira um namoro com outro homem. A frase isolada "vou te matar", então, poderia ter seu sentido reconstruído mediante o seguinte diálogo:

Homem: Você está mesmo namorando???? Não signifiquei nada para você?

Mulher: Minha vida não é da sua conta.

Homem: Conheço seus horários e sua rotina.

Mulher: Você está me ameaçando?

Homem: Não estou ameaçando. Estou avisando. Vou te matar.

Imagine-se, por outro lado, que a produção de outras provas revelasse não esse contexto de um namoro terminado, mas o contexto de um escritório de advocacia, em que se descobrisse que se tratava de dois(duas) sócios(as), sendo que um(a) sócio(a) sempre esquecia de enviar um relatório mensal para o cliente e sempre era cobrado(a) pelo(a) outro(a) sócio(a) por isso. O sentido do diálogo poderia, neste caso, ser reconstruído da seguinte forma:

Sócio(a) 1: Não vai me dizer que você esqueceu de novo de mandar o relatório para o cliente?!?!

Sócio(a) 2: MEU DEUS!

Sócio(a) 1: Estou avisando. Vou te matar!

Naturalmente, as mesmas palavras "vou te matar" ganham, aqui, por conta do contexto, um sentido totalmente diferente. Afinal, esse demonstraria que não se trata de uma ameaça, mas sim da utilização da 
expressão "vou te matar" de uma forma figurada, com o sentido de "estou bravo(a), chateado(a) com você". E o mesmo poderia ocorrer caso as ulteriores provas produzidas em relação à gravação demonstrassem se tratar de um contexto entre dois amigos(as), quando um(a) houvesse postado uma fotografia do(a) outro(a) nas redes sociais:

Amigo(a) 1: Você postou aquela fotografia nossa? Eu estou com uma cara horrorosa!

Amigo(a) 2: Agora já foi! [Risos].

Amigo(a) 1: Sacanagem! [Risos].

Amigo(a) 2: Você não viu a próxima que eu vou postar!

Amigo(a) 1: Nem pense nisso. Estou avisando. Vou te matar!

Em qualquer dos três exemplos, seria imprescindível, portanto, para a compreensão do sentido, a obtenção de "toda a conversa". Entretanto, em casos reais, como o que será apresentado no capítulo que segue, nem sempre a totalidade do contexto está estampada em um só elemento de prova, isto é, em uma só ligação. E muitas vezes o contexto que ressai de uma só ligação, pela falta de comprehensiveness, traz um resultado de corroboração muito baixo.

Assim, a título de resumo do presente item, pode-se dizer que a lição da epistemologia para o presente estudo é que é imprescindível para a efetiva reconstrução de sentidos a busca pela maior comprehensiveness, isto é, para a maior completude possível do material probatório e da combinação de elementos de prova. Afinal, sem isso, uma prova isolada, ou mesmo um palpite sobre o sentido possível desprovido de provas, pode levar a resultados e interpretações desastrosos.

\section{0 problema e formas de Solução. A neCESsidade da prova DO CONTEXTO PARA A INTERPRETAÇÃO DA LINGUAGEM}

\subsection{PROBLEMA}

A interceptação telefônica (ou interceptação em sentido estrito) recebe atenção da doutrina principalmente em relação à sua definição como “captação da comunicação telefônica alheia por um terceiro, sem o 
conhecimento de nenhum dos comunicadores" ${ }^{32}$, tratando-se de meio de obtenção de prova irrepetível por sua natureza ${ }^{33}$. Discutem-se, em geral, os requisitos para o deferimento da interceptação ${ }^{34}$, a duração legalmente autorizada para a medida ${ }^{35}$, a necessidade ou não de transcrição dos diálogos obtidos e o procedimento para sua execução, desde a decretação até a inutilização.

A doutrina, com razão, coloca bastante ênfase na necessidade de que o resultado obtido a partir da interceptação seja submetido a contraditório diferido "tão logo se considere que o conhecimento do resultado da diligência não importará em prejuízo ao prosseguimento das investigações ou do processo" 36 ; tudo isso a fim de que possa "discutir a prova em todos os seus aspectos" ${ }^{37}$. Entre tais aspectos, entretanto, o destaque é dado à (i)licitude da prova, à idoneidade técnica da operação, à autenticidade, à identificação ou não da própria voz etc. ${ }^{38}$

Por outro lado, não resta abordada, em geral, questão que, na minha opinião, possui máxima importância: como seria possível conhecer o sentido de um diálogo, ou de palavras empregadas? É possível

32 LIMA, Renato Brasileiro de. Manual de Processo Penal. $8^{a}$. Ed. Salvador: JusPodivm, 2020, p. 813. Em sentido análogo, PRADO, Geraldo. Limite às Interceptações Telefônicas e a Jurisprudência do Superior Tribunal de Justiça. Rio de Janeiro: Lumen Juris, 2005, p. 50. BADARÓ, Gustavo. Processo Penal. $8^{\mathrm{a}}$. Ed. São Paulo: RT, 2020, p. 592; CAMBI, Eduardo. "Interceptação Telefônica Breves Considerações Sobre A Lei 9.296/1996”. Revista de Processo, vol. 118, Nov - Dez. p. 143-148, 2004.

33 LOPES JR., Aury. Direito Processual Penal. 17a . Ed. São Paulo: Saraiva Educação, 2020, p. 283.

34 LIMA, Renato Brasileiro de. Manual de Processo Penal. $8^{\text {a }}$. Ed. Salvador: JusPodivm, 2020, p. 827. No mesmo sentido, vide BADARÓ, Gustavo. “A Boca do Leão: Validade das Interceptações Telefônicas Decretadas com Base em notitia criminis anônima”. Revista dos Tribunais, vol. 927, 2013, p. 529-553.

35 LOPES JR., Aury. Direito Processual Penal. 17ª Ed. São Paulo: Saraiva Educação, 2020, p. 263-264.

36 LIMA, Renato Brasileiro de. Manual de Processo Penal. $8^{\mathrm{a}}$. Ed. Salvador: JusPodivm, 2020, p. 847.

37 BADARÓ, Gustavo. Processo Penal. 8a . Ed. São Paulo: RT, 2020, p. 611.

38 Em sentido similar, LIMA, Renato Brasileiro de. Manual de Processo Penal. $8^{\mathrm{a}}$. Ed. Salvador: JusPodivm, 2020, p. 848; BADARÓ, Gustavo. Processo Penal. $8^{\mathrm{a}}$. Ed. São Paulo: RT, 2020, p. 611. 
simplesmente a quem ouve uma gravação ou lê a transcrição de um diálogo simplesmente acessar o seu sentido diretamente? Como saber se a reconstrução dos sentidos de um diálogo obtido em interceptação telefônica espelha, de fato, o sentido empregado pelas pessoas que dialogavam?

Depois de, nos itens anteriores do presente artigo, trabalhar com casos ideias, para chegar no ponto central do presente estudo utilizarei dois diálogos reais, retirados do contexto de interceptações telefônicas feitas na Operação Costeira, deflagrada no Rio Grande do Sul pela Polícia Federal em 2009 $9^{39}$, investigando a ocorrência de operações ilegais de câmbios. Não pretendo analisar o caso, ou a forma como cada um dos atores se comportou, mas tão somente tomar dois diálogos reais (com nomes alterados) emprestados, a fim de questionar a forma como os possíveis sentidos poderiam, em tese, ser atribuídos, para um e para outro lado.

DIÁLOGO 1

$B$ - Viu.

A - Ham.

B O João não quis cebola naquele preço. Ele quer o preço que o coisa deu aí... que o secretário deu pra ele. Tá?

A - Ahm... só um pouquinho...

$B$ - Tá.

A - É que... é que esse preço é à vista que nós podemos fazer o saco, entendeu?

B - Eu sei, eu sei, é que eu dei aquele preço pra o... o combinado pois é... A - Sim, não, mas então deixa quieto, é que aquele preço é à vista, né? Não tem como fazer.

B - Tá bem.

DIÁLOGO 2

(...)

C - Hum, fechei, fechei com o Pedro 26 e meio de alface.

$D$ - Hã, hã.

C - Aí ele vai acertar terça-feira, 198 aqui, bom né?

39 Processo 5022583-62.2012.4.04.7100, que tramitou na $7^{\mathrm{a}}$. VF de Porto Alegre. O processo já se encontra baixado, transitado em julgado, sendo seu acesso público e irrestrito. Os nomes das pessoas foram omitidos e/ou alterados. 
$D$ - Sim, ele pegou em vez de peso, verde.

$C$ - Não, esse é outro negócio sabe, ele pegou.

$D$ - Ah, outro.

C - 6 e meio e esse, esse que eu te falei antes, só de noite ele vai me confirmar, sabe?

$D$ - Tá.

$C$ - Ele tem que ver se vai se concretizar o negócio, e, e, só que daí.

$D$ - E o dos, dos pesos.

$C$ - Sim, esse ele vai me confirmar de noite se vai fechar o negócio dele, né.

$D$ - Hã, hã.

C - Tá sem preço, ele não reclamou nada, só de noite vai me dar a resposta, daí agora ele me ligou e pediu uns 26 e meio, daí fiz 198 pra terça-feira.

$D$ - Hã, hã.

$C$ - Entendeu.

$D$ - Hã, hã, tá.

C - E daí, daí acho que por enquanto não vou fechar nada né, lá embaixo, vamo ver amanhã como vai se comportar.

Apresentado tal caso, nos itens que seguem abordarei os inúmeros desafios que tais diálogos podem significar.

\subsection{A INDEXICALIDADE DO SOM, O SIMBOLISMO DA LINGUAGEM E A NECESSIDADE DE BUSCA DE SENTIDOS POSSÍVEIS}

O primeiro ponto, considerando a indexicalidade dos sons, é saber quais palavras foram pronunciadas, de fato, pelas pessoas que falavam ao telefone; e isso a fim de que eventual transcrição seja fidedigna, correspondente à realidade ${ }^{40}$. Caso haja uma falha nessa primeira etapa,

40 Apesar da referência legal à "possibilidade" de gravação (art. $6^{\circ}$. § $1^{\circ}$. da lei 9296/96), no atual estágio de desenvolvimento das tecnologias entendo que tem razão BADARÓ, Gustavo. Processo Penal. 8 $^{\text {a }}$. Ed. São Paulo: RT, 2020, p. 606, para quem "todas as interceptações devem ser gravadas, sob pena de impossibilitar o exercício do contraditório e da ampla defesa em relação ao seu conteúdo" (no mesmo sentido, SANTORO, Antonio Eduardo Ramires; 
naturalmente, todo e qualquer processo de interpretação posterior já estará fadado ao fracasso. As palavras que foram ditas nada mais são do que parte da própria indexicalidade do áudio: variando as palavras, varia, também, o áudio, devendo isso ser refletido na transcrição.

Em um caso ocorrido nos Estados Unidos ${ }^{41}$, por exemplo, o policial Jim Barton alegou ter chegado em casa e encontrado sua esposa morta, efetuando ligação para a central de emergências (911). Após 10 anos sem que fossem encontrados suspeitos, uma equipe de cold cases reanalisou a gravação da ligação para a central de emergências, tornando-se central para o caso saber se Jim teria dito, na ligação, "I gotta call for help" ("preciso ligar para pedir ajuda") ou "I gotta call Phelps" ("preciso ligar

TAVARES, Natália Lucero Frias; GOMES, Jefferson de Carvalho. "O protagonismo dos sistemas de tecnologia da informação na interceptação telefônica: a importância da cadeia de custódia”. Revista Brasileira de Direito Processual Penal, v. 3, n. 2, p. 605-632, 2017, p. 616. Apesar de o art. $6^{\circ}$. § $1^{\circ}$. da lei $9296 / 96$ referir que, uma vez gravada, "será determinada a sua transcrição", a jurisprudência vem adotando o entendimento de ser desnecessária a transcrição integral dos diálogos. Nesse sentido, por exemplo "PROCESSUAL PENAL. AGRAVO DE INSTRUMENTO. CERCEAMENTO DE DEFESA. INDEFERIMENTO DE DILIGÊNCIA PROBATÓRIA. OFENSA REFLEXA. INTERCEPTAÇÕES TELEFÔNICAS JUDICIALMENTE AUTORIZADAS. DEGRAVAÇÃO INTEGRAL. DESNECESSIDADE. AGRAVO IMPROVIDO. I - Este Tribunal tem decidido no sentido de que o indeferimento de diligência probatória, tida por desnecessária pelo juízo a quo, não viola os princípios do contraditório e da ampla defesa. Precedentes. II - No julgamento do HC 91.207-MC/RJ, Rel. para o acórdão Min. Cármen Lúcia, esta Corte assentou ser desnecessária a juntada do conteúdo integral das degravações das escutas telefônicas, sendo bastante que se tenham degravados os excertos necessários ao embasamento da denúncia oferecida. III - Impossibilidade de reexame do conjunto fático probatório. Súmula 279 do STF. IV - Agravo regimental improvido" (STF, 1a. Turma. Agravo Regimental no AI 685878. Rel. Min. Ricardo Lewandowski, j. em 05/05/2009, dj 12/06/2009). Parece-me ter razão, ademais, LIMA, Renato Brasileiro de. Manual de Processo Penal. $8^{\text {a }}$. Ed. Salvador: JusPodivm, 2020, p. 846, ao afirmar que apesar de não haver "necessidade de transcrição total das gravações, é dever do Estado disponibilizar a integralidade das conversas captadas, sendo inadmissível a sua seleção pelas autoridades da persecução de partes dos áudios interceptados". Retornarei ao ponto no final do presente item.

Uma notícia sobre os desdobramentos do caso pode ser vista em https// www.cleveland19.com/story/33286227/thomas-jim-barton-guilty-plea/. Último acesso em 17/07/2020, às 20, p.01. O caso foi objeto do episódio Chief Suspect, da série Forensic Files, temporada 11, episódio 23, transmitido em 20/12/2006. 
para o Phelps"). Jim acabou condenado, entendendo-se que a referência seria a seu meio-irmão, William Phelps, que, de acordo com investigações ulteriores, teria sido contratado pelo policial para "dar um susto" na sua esposa, tendo acabado por matá-la.

Uma vez feitas as transcrições a partir dos dados obtidos a partir da interceptação, ou simplesmente guardados em gravações, passa-se à fase de busca pela interpretação de sentidos possíveis, isto é, de reconstrução de sentidos. E o problema que se coloca, então, é o seguinte: sabendo que os símbolos não possuem uma relação causal automática com os fatos do "mundo lá fora”, como é possível distinguir uma mensagem cifrada, cujo intuito é justamente ocultar a prática de atos ilícitos, de uma mensagem comum, fruto de uma comunicação ordinária do dia a dia?

É importante notar, nesse passo, que incumbe às autoridades a busca pelo entendimento do hábito coletivo da comunicação em questão, algo que, conforme demonstrado no item anterior, somente pode ser feito mediante a obtenção de novas provas e da combinação entre vários elementos. O mero fato, em si, de alguém comunicar-se com outrem em linguagem cifrada, ou em alguma linguagem que não seja entendida pela autoridade policial, por exemplo, não configura qualquer ilicitude.

Em primeiro lugar, deve-se ter em conta toda a pluralidade de sentidos literais possíveis para aquele contexto ${ }^{42}$. É certo que um texto que menciona a palavra "cachorro" faz com que o proprietário de um dogue alemão faça a associação "cachorro = dogue alemão", ao passo que um proprietário de poodle faz a associação "cachorro = poodle" ${ }^{43}$. Ambos são sentidos literais, denotativos, pois tanto o dogue alemão quanto o poodle são cachorros $^{44}$. Nos diálogos acima, está-se referindo, de fato, a cebolas

42 Sobre interpretação e pluralidade de sentidos quanto à interpretação de textos legais, vide GUASTINI, Riccardo. Interpretare e Argomentare. Milão: Giuffrè, 2011, p. 39.

43 Isso, conforme abordado em PAULA RAMOS, Vitor de. "Respeite as Regras!". Revista da Faculdade de Direito Dom Alberto, v. 1, p. 40-57, 2013, por si só traz alguns problemas para a interpretação de textos legais, visto que uma regra de condomínio que determine que cachorros sejam carregados no colo dentro do elevador soará muito natural para o dono de um poodle, mas absolutamente bizarra e irrealizável para o dono de um dogue alemão.

44 Daí que ECO, Umberto. Dire Quasi la Stessa Cosa. Milão: Bompiani, 2003, p. 35 refira que "a sinonímia seca não existe". Afinal, se o "tradutor italiano de 
e alfaces? Ou se trataria de alguma linguagem cifrada? A palavra "peso" está empregada como o nome de uma moeda ("peso argentino", "peso uruguaio"), ou como peso no sentido de "pesado" ou "leve"?

Reconhecendo-se que uma só palavra pode, também, possuir sentidos denotativos e conotativos, deve-se, também, analisar se as palavras estão sendo utilizadas em sentidos denotativos ou conotativos. Em um dos livros mais importantes da história da literatura brasileira, Grande Sertão: Veredas (João Guimarães Rosa), o leitor acompanha a travessia de Riobaldo por diversas estradas, veredas. A palavra "estrada" tem, em língua portuguesa, indubitavelmente o sentido literal de um caminho, de um percurso por onde se pode passar para ir de um lugar a outro; na obra, entretanto, utiliza-se tal palavra em um sentido conotativo, significando a "estrada da vida" 45 . O leitor que capte somente o sentido denotativo da estrada perderá, portanto, o sentido conotativo, a referência à vida.

Da mesma forma, nos diálogos acima, "lá embaixo" pode referir-se realmente a algo que está em uma altura menor (em um porão, em um sótão), ou a algo, por exemplo, em localização geográfica de menor altitude (como quando se diz que alguém que vai da Serra para o nível do mar vai "descer" para a cidade).

A combinação de uma palavra com outra já pode, também, atrair sentidos diferentes para uma expressão. Novamente, duas ou mais palavras juntas podem ter um sentido literal associado, como é o caso das palavras "panela de pressão". A palavra panela, sozinha, denota o recipiente em que se cozinha; a pressão, sozinha, refere-se ao conceito físico, da relação entre uma força e a área. Ao fazer-se referência a "panela de pressão", entretanto, faz-se referência a um tipo específico de panela, que utiliza a pressão alta para diminuir o tempo de cocção.

La peste tivesse dito que o doutor Rieux havia visto nas escadas o cadáver de um mamífero roedor, não teria feito (...) um bom serviço ao texto original” (ECO, Umberto. Dire Quasi la Stessa Cosa. Milão: Bompiani, 2003, p. 87), ainda que "mamífero roedor" seja uma definição de "morcego".

45 Os exemplos são inúmeros da palavra "estrada" no sentido conotativo de "vida”. É o caso, ainda na literatura brasileira, de Morte e Vida Severina (de João Cabral de Melo Neto); no cancionário brasileiro, da mesma forma, fala-se a respeito de Travessia, na canção homônima de Milton Nascimento, e da Infinita Highway, na canção homônima de Engenheiros do Hawaii. 
Há outros casos em que as palavras, quando associadas, gerarão um sentido conotativo. Novamente em língua portuguesa, a palavra "boi" é utilizada para denotar um animal bovino de sexo masculino. A expressão "boi de piranha”, entretanto, trás consigo, em algumas regiões do Brasil, um sentido conotativo, da ideia derivada de um boi que, por sua especial fraqueza ou pouco valor, seria sacrificado para que o rebanho pudesse atravessar um rio; o "boi de piranha" entraria primeiro n'água, sendo entregue às piranhas, sendo, assim, sacrificado para que o resto do rebanho pudesse passar em segurança. A expressão, portanto, tem o sentido conotativo de casos em que algo de pouco valor é sacrificado para que outro(s) mais valiosos sejam preservados.

Nos diálogos acima, portanto, em tese, as palavras associadas " 26 e meio de alface" e "ele vai (...) acertar 198 aqui" podem denotar e conotar muitas coisas. Por exemplo: "26,5kg de alface", "26,5 pés de alface”, "26 sacos e meio de alface” etc.; "198 reais em alface”, "198 dólares em alface", "198 caixas de alface" etc.

Por fim, diversas frases combinadas em um texto, em um livro, ou em qualquer conjunto de símbolos, podem possuir um sentido global diferente de cada símbolo individual. O leitor de A Caverna, do escritor português José Saramago, somente compreenderá a relação do oleiro Cipriano Algor, sua filha e genro com a alegoria da caverna ao final do livro, pois somente nos últimos capítulos as informações necessárias para tal interpretação são dadas. O leitor que chegar somente à metade do livro, portanto, poderá compreender o sentido literal e o conotativo das palavras e das frases, mas não poderá compreender o sentido do todo.

Nos diálogos acima, por outro lado, ao contrário do que ocorre com um livro ou um filme, a totalidade de informações necessárias para a interpretação correta não está necessariamente nos diálogos havidos. $\mathrm{O}$ diálogo 1, acima, analisado somente do ponto de vista interno, demonstra um todo coerente, mas assim mesmo não necessariamente representa, de fato, uma mera compra e venda de cebolas. E o diálogo 2, cuja interpretação isolada possui elementos incoerentes - por exemplo, "ele pegou em vez de peso, verde" -, não confirma, de maneira isolada, a prática ou não de algum ilícito.

Surgem aqui duas consequências extremamente importantes, que permitirão um maior rigor epistêmico no tratamento dos diálogos obtidos 
mediante interceptações. A primeira é que todas as interceptações devem ser objeto de gravações ${ }^{46}$, e tais gravações devem ser integralmente mantidas $^{47}$, pelo menos até que seja possível a realização de contraditório ${ }^{48}$.

Se assim não fosse - e caso se permitisse uma "filtragem" do material ${ }^{49}$ destruindo-se o restante sem outros cuidados -, no exemplo dado acima, formulada uma hipótese durante a investigação, a destruição do restante do material não permitiria que tal hipótese fosse colocada em dúvida ou criticada. Assim, por exemplo, permitindo-se a destruição

46 BADARÓ, Gustavo. Processo Penal. 8ª Ed. São Paulo: RT, 2020, p. 606; SANTORO, Antonio Eduardo Ramires; TAVARES, Natália Lucero Frias; GOMES, Jefferson de Carvalho. "O protagonismo dos sistemas de tecnologia da informação na interceptação telefônica: a importância da cadeia de custódia”. Revista Brasileira de Direito Processual Penal, v. 3, n. 2, p. 605-632, 2017, p. 616.

47 Nesse sentido, PRADO, Geraldo. Prova Penal e Sistema de Controles Epistêmicos. A quebra da cadeia de custódia das provas obtidas por métodos ocultos. São Paulo: Marcial Pons, 2014, p. 79. No mesmo sentido, PRADO, Geraldo. A cadeia de custódia da prova no processo penal. São Paulo: Marcial Pons, 2019, p. 124; SOUZA, Lia Andrade; VASCONCELLOS, Vinicius. "A cadeia de custódia da prova obtida por meio de interceptações telefônicas e telemáticas: meios de proteção e consequências da violação". Revista Da Faculdade De Direito (UFPR), v. 65, p. 31-48, 2020, p. 39. Não abordo em profundidade aqui o problema da forma como as gravações devem ser custodiadas, bastando, para o escopo do presente artigo, referir a necessidade de autenticação no sentido estadunidense. Na regra 901 das Federal Rules of Evidence, nesse sentido, vai dito que, para que um elemento de prova seja considerado autêntico, a parte que o apresenta tem o ônus de oferecer provas suficientes para amparar uma decisão [to support a finding] de que o item "é o que a parte afirma ser". Sobre o tema vide ALLEN, Ronald J.; KUHNS, Richard B.; SWIFT, Eleanor; SCHWARTZ, David S.; PARDO, Michael S. Evidence. Text, problems, and cases. 5a. ed. Frederick: Kluwer, p. 187; MUELLER, Christopher B.; KIRKPATRICK, Laird C. Evidence. [1988]. 5a. ed. Frederick: Kluwer, 2012, p. 1083. A cadeia de custódia é um dos elementos para tanto, mas, como refere BADARÓ, Gustavo. "A cadeia de custódia e sua relevância para a prova penal”. In: SIDI, Ricardo; LOPES, Anderson B. (orgs.) Temas atuais da investigação preliminar no processo penal. Belo Horizonte: D’ Plácido, p. 517-538, 2018, p. 529, no contexto das interceptações telefônicas "confundiu-se a cadeia de custódia, entendida como a documentação da cadeia de custódia - ainda que de algo imaterial - como o conteúdo das conversas telefônicas - com a própria existência da fonte de prova". lo: Saraiva Educação, 2020, p. 657. 
prematura do material, um diálogo que revelasse, no exemplo dado acima, um comércio normal de alfaces e cebolas poderia ser eliminado, fazendo com que os demais diálogos parecessem, isoladamente, mais suspeitos ou mais incriminadores.

A segunda consequência, derivada da primeira, é que para o pleno exercício da defesa e do próprio direito à prova, a defesa deve ter acesso integral às gravações ${ }^{50}$. Afinal, "trechos de conversa [que], para uma parte, possam não ter interesse para a prova, (...) para a outra parte podem ser de extrema relevância" ${ }^{1}$. $\mathrm{O}$ acesso à integralidade das gravações possibilitará a formulação de hipóteses alternativas para os sentidos possíveis aos diálogos. Em outras palavras, sem o acesso integral, a defesa não teria condições de utilizar outras das gravações obtidas no mesmo contexto de interceptação para arguir diverso "uso dado a estas palavras pelas pessoas investigadas, no contexto da investigação" ${ }^{2}$; por exemplo, no caso acima,

50 Nesse sentido, o STJ já reconheceu violar o direito à prova e à paridade de armas a ausência de manutenção da integralidade do material colhido na investigação (STJ, 6 ${ }^{\mathrm{a}}$. Turma. HC 160.662/RJ. Rel. Min. Assusete Magalhães, j. em 18/02/2014, dj 17/03/2014). Nesse sentido, referiu a corte que "[a] pesar de ter sido franqueado o acesso aos autos, parte das provas obtidas a partir da interceptação telemática foi extraviada, ainda na Polícia, e o conteúdo dos áudios telefônicos não foi disponibilizado da forma como captado, havendo descontinuidade nas conversas e na sua ordem, com omissão de alguns áudios. (...) A prova produzida durante a interceptação não pode servir apenas aos interesses do órgão acusador, sendo imprescindível a preservação da sua integralidade, sem a qual se mostra inviabilizado o exercício da ampla defesa, tendo em vista a impossibilidade da efetiva refutação da tese acusatória, dada a perda da unidade da prova". No mesmo sentido, STJ, $6^{\mathrm{a}}$. Turma. REsp 1.795.341/RS. Rel. Min. Nefi Cordeiro, j. 07/05/2019, dje 14/05/2019, em que a corte referiu que "deve ser facultado à defesa a integralidade das conversas advindas nos autos de forma emprestada, sendo inadmissível a seleção pelas autoridades de persecução acerca das partes a serem extraídas, mormente quando atestado no Tribunal de origem a existência de áudios descontinuados, sem ordenação, sequencial lógica e com omissão de trechos da degravação, como ocorre nestes autos". Para comentários a respeito da jurisprudência do STJ sobre o tema, vide ÁVILA, Gustavo Noronha; BORRI, Luiz Antonio. “A Cadeia de Custódia da Prova no 'Projeto de Lei Anticrime': Suas Repercussões em um Contexto de Encarceramento em Massa”. Direito Público, v. 89, p. 114-132, 2019, p. 121.

51 BADARÓ, Gustavo. Processo Penal. $8^{\text {a }}$. Ed. São Paulo: RT, 2020, p. 611.

52 FANTINI, Daniel Fabio. “Interceptação Telefônica e Linguagem”. Revista Brasileira de Ciências Policiais, v. 3, n. 1, p. 11-25, jan/jun 2012, p. 17. 
demonstrando, por outros diálogos obtidos no mesmo contexto de interceptação, que a palavra "peso" vinha utilizada habitualmente no sentido de quilogramas (e não no de moedas, como "peso argentino").

Uma vez efetuadas e mantidas as gravações, entretanto, o problema não estará resolvido; e isso porque será necessário, para fazer a interpretação adequada, uma excelente apuração dos fatos, combinando-se os diálogos obtidos pela interceptação com outras provas. É o que será abordado no capítulo a seguir.

\subsection{A BUSCA PELA CORROBORAÇÃO DAS HIPÓTESES E O PESO DA COMBINAÇÃO DE PROVAS}

Sabendo-se que o valor dos símbolos, como a linguagem, depende de que se entenda o contexto da sua criação, deve-se necessariamente recorrer à combinação de provas. Afinal, sendo relevante para a determinação de sentidos saber o hábito coletivo da comunicação em questão, é necessário reconhecer a qual contexto pertence aquela comunicação $0^{53}$. Quem são as pessoas? Em que situação foram gravadas? Em que local? Em que época? E a grande dificuldade, como mencionado, é que, em casos reais, os contextos e os elementos indispensáveis para a interpretação dificilmente estarão integralmente nas ligações gravadas.

Retornando-se ao caso real, das cebolas e alfaces, dever-se-ia, de fato, apurar se as pessoas em questão, de fato, vendem cebolas ou alfaces. E, ainda, que vendam, se tais vendas de cebolas e alfaces, de fato, são o objeto principal de seu comércio, ou se são usadas como forma de mascarar práticas ilícitas.

Três seriam os fatos que teriam que ser provados, portanto, a fim de que nos diálogos acima fosse possível utilizar o diálogo como prova da prática de algum ato ilícito: (i) que a venda de cebola ou de alface, naquele contexto de comunicação, não significaria, de fato, a venda de cebolas ou de alfaces; (ii) que, naquele contexto, significaria alguma transação ilícita; (iii) que a transação ilícita mencionada realmente teria ocorrido da forma como descrita no áudio.

53 FANTINI, Daniel Fabio. “Interceptação Telefônica e Linguagem”. Revista Brasileira de Ciências Policiais, v. 3, n. 1, p. 11-25, jan/jun 2012, p. 17. 
Formada a hipótese de que "cebola" ou "alface", nesse contexto, significaria outra coisa, portanto, seria necessário, submeter tal hipótese a provas, seja para confirmá-la, seja para afastá-la.

Caso, por exemplo, fosse demonstrado que as pessoas em questão não vendem cebolas ou alfaces, isso significaria um passo no sentido da corroboração de não se estar tratando, de fato, de compra e venda de cebolas. Por outro lado, caso as pessoas em questão, de fato, vendessem cebola e alface, a hipótese do uso da palavra no sentido literal não poderia ser descartada, devendo ser objeto de outras provas.

Da mesma forma, se alguém combinasse a entrega de diversos sacos de cebola ou de diversos pés de alface para outrem em determinado lugar e em determinado horário e dia, aparecendo somente com um envelope na mão, no dia e horário combinados, haveria corroboração no sentido de não se tratar de cebolas ou alfaces.

Imaginando-se, a seguir, que as provas demonstrem não se tratar de "cebolas" ou "alfaces", passar-se-ia à busca pelo sentido real. Imaginam-se, então, a hipótese de que "cebolas", na comunicação em questão, signifique euros e de que "alface" signifique dólares. Como testar essa hipótese, para confirmá-la ou refutá-la? Novamente mediante o recurso à prova combinada - afinal, o mero fato de "cebola" não significar "cebola" e "alface" não significar "alface”, no contexto em questão, com efeito, não se trata, isoladamente, como já mencionado anteriormente, da prova de algum fato ilícito (o sujeito pode, por exemplo, chamar algum produto lícito, para fins de sua comunicação, de cebola ou de alface).

Por fim, ainda que haja provas de que cebola significa, de fato, euros, e de que alface significa dólares, e de que uma transação de venda ilícita de euros ou de dólares seja descrita em um telefonema, é necessário corroborar o que é dito com o que, de fato, é feito. Isso principalmente diante de símbolos, como a linguagem, cuja característica, como visto, é da inexistência de relação causal automática com a realidade. Alguém que fala que vai vender dólares ilicitamente não necessariamente, de fato, vende dólares ilicitamente.

Novamente, tal diferenciação somente poderá ser feita mediante o recurso da prova combinada, isso é, com a busca pela maior completude. Nesse passo, é importante destacar um ponto extremamente importante, salientado pela epistemologia: um elemento de prova pode ter um peso 
muito maior dentro de um conjunto probatório do que o peso que teria sozinho $^{54}$, isto é, individualmente ${ }^{55}$. Afinal, o "encaixe" de uma prova na outra aumenta o grau de corroboração de conjunto ${ }^{56}$. No caso dos diálogos obtidos a partir de interceptação telefônica isso é bastante visível.

Usando os casos acima, mesmo que não exista uma prova (um elemento) que possa, individualmente, ser suficiente para superar o grau necessário para a condenação, o peso das provas combinadas, em um conjunto, pode ser suficiente.

Se, por exemplo, se verifica que os sujeitos em questão não vendem cebolas ou alfaces, que eles aparecem em diversas gravações combinando encontros para entrega em que são dados envelopes, se a cotação passada por telefone não tem relação com a cotação de cebolas ou alfaces, mas é muito próxima à cotação de dólares e euros etc., poder-se-á chegar, com o conjunto probatório, a um grau de corroboração suficiente.

Se, por outro lado, a hipótese de tratar-se de euros ou dólares não vier corroborada por outras provas, ou se, ao testar a hipótese, houver hipóteses contrárias que não sejam superadas, o conjunto não permitirá que se conclua pela prática do crime em questão.

A importância da prova combinada, em resumo, é cabal. Voltando-se ao exemplo da troca de mensagens entre os sócios, dado no item anterior, imagine-se se todo o diálogo tivesse sido travado por telefone, tendo somente a última frase sido enviada por Whatsapp e, por uma infeliz coincidência, o sócio que esquecera de enviar o relatório tivesse sido, 20 minutos depois da mensagem, assassinado. O sócio sobrevivente, quando encontrada a mensagem, certamente seria visto com muita suspeição, de

54 HAACK, Susan. Evidence Matters. Science, Proof, and the Truth in the Law. New York: Cambridge University Press, 2014, p. 208-238.

55 Sobre a valoração da prova individualmente e em conjunto, vejam-se, por todos, FERRER BELTRÁN, Jordi. La Valoración Racional de la Prueba. Madrid: Marcial Pons, 2007, esp. pp. 126 e ss. e TARUFFO, Michele. La Prova nel Processo Civile. Milão: Giuffrè, 2012, pp. 207 e ss.

56 O STJ já decidiu, por exemplo, que “(...) a condenação (...) encontra-se fundamentada nos diálogos interceptados e também em outras provas produzidas durante a instrução criminal, notadamente na prova testemunhal, não havendo que se falar em condenação lastreada exclusivamente nas provas obtidas pela interceptação telefônica”. STJ, 5 . Turma, HC 384.524/SP, Rel. Min. Felix Fischer, j. em 16/05/2017, DJ 25/05/2017. 
modo que seria imprescindível produzir outras provas para verificar se realmente se tratava de uma ameaça ou não.

A necessidade de busca pela completude tendencial do material probatório, além de provas a respeito do contexto de produção desse, possibilitará, portanto, e entre outras coisas, a análise do "hábito coletivo" de referência, confirmando-se ou refutando-se, com novas provas, também a ocorrência ou não dos fatos.

Chegados a esse ponto, para concluir, é necessário finalizar respondendo os dois questionamentos formulados ao início: (i) a reconstrução de sentidos de textos, palavras ou frases pode se dar de maneira independente do contexto de sua utilização? Claramente, por tudo o que foi exposto ao longo do presente artigo, não, pois tratando-se de símbolos, não há relação automática com a realidade, sendo necessário o conhecimento a respeito do contexto de comunicação relevante; e (ii) como é possível conhecer o contexto de uma comunicação? Mediante a busca pela completude tendencial do material probatório, além de provas a respeito do contexto de produção desse.

\section{Conclusões}

A gravação de uma ligação telefônica possui elementos de indexicalidade e de simbolismo, sendo necessário atentar para ambos na busca de sentidos para a linguagem utilizada.

A tentativa de formação de hipóteses a respeito dos sentidos é bastante salutar, e parte de qualquer processo de apuração dos fatos, mas não pode, em relação aos símbolos, ser suficiente para que uma hipótese possa ser considerada provada.

É necessário, antes de qualquer coisa, manter as gravações efetuadas, pelo menos até que seja possível o contraditório, dando-se acesso integral à defesa. Após, para a adequada reconstrução de sentidos, é necessária a análise individual de cada prova, de modo que o intérprete busque entender os contextos em que as palavras, frases e conversas são utilizadas; para isso recorrendo a sentidos denotativos e conotativos do hábito comum, de eventuais coletividades, ou mesmo de duas pessoas. 
Uma vez formuladas hipóteses, essas devem ser testadas e retestadas, mediante o aporte de novas provas: a maior completude do material probatório poderá afastar algumas e corroborar outras, sendo certo, de qualquer forma, que o standard probatório aplicável deverá, em qualquer caso, ser superado, a fim de que seja possível a condenação ${ }^{57}$.

\section{BibliografiA}

ALLEN, Ronald J.; KUHNS, Richard B.; SWIFT, Eleanor; SCHWARTZ, David S.; PARDO, Michael S. Evidence. Text, problems, and cases. 5a. ed. Frederick: Kluwer.

ÁVILA, Gustavo Noronha; BORRI, Luiz Antonio. A Cadeia de Custódia da Prova no 'Projeto de Lei Anticrime': Suas Repercussões em um Contexto de Encarceramento em Massa. Direito Público, v. 89, p. 114-132, 2019.

ÁVILA, Humberto. Teoria dos princípios: da definição à aplicação dos princípios jurídicos. 18a. Ed. São Paulo: Malheiros Editores, 2018.

BADARÓ, Gustavo. A Boca do Leão: Validade das Interceptações Telefônicas Decretadas com Base em notitia criminis anônima. Revista dos Tribunais, vol. 927, p. 529-553, 2013.

BADARÓ, Gustavo. A cadeia de custódia e sua relevância para a prova penal. In: SIDI, Ricardo; LOPES, Anderson B. (orgs.) Temas atuais da investigação preliminar no processo penal. Belo Horizonte: D’Plácido, p. 517-538, 2018.

BADARÓ, Gustavo. Epistemologia Judiciária e Prova Penal. São Paulo: RT, 2019.

BADARÓ, Gustavo. Processo Penal. 8a. Ed. São Paulo: RT, 2020.

CAMBI, Eduardo. Interceptação Telefônica - Breves Considerações Sobre A Lei 9.296/1996. Revista de Processo, vol. 118, p. 143-148, nov./dez. 2004.

CARNELUTTI, Francesco. La Prova Civile. 2a. ed. Roma: Edizioni dell'Ateneo, 1947.

CLERMONT, Kevin M. Standards of Decision in Law. Durham: Carolina Academic Press, 2013.

57 Sobre standards probatórios vide CLERMONT, Kevin M. Standards of Decision in Law. Durham: Carolina Academic Press, 2013, esp. p. 11; BADARÓ, Gustavo. Epistemologia Judiciária e Prova Penal. São Paulo: RT, 2019, p. 237. 
CORDERO, Franco. Procedura Penale. 9ª Ed. Milão: Giuffrè, 2012.

ECO, Umberto. La Struttura Assente. Introduzione alla Ricerca Semiologica. Milano: Ed. Bompiani, 1968.

ECO, Umberto. Dire Quasi la Stessa Cosa. Milão: Bompiani, 2003.

FANTINI, Daniel Fabio. “Interceptação Telefônica e Linguagem”. Revista Brasileira de Ciências Policiais, v. 3, n. 1, p. 11-25, jan/jun 2012. https://doi.org/10.31412/ rbcp.v3i1.39

FERRER BELTRÁN, Jordi. La Valoración Racional de la Prueba. Madrid: Marcial Pons, 2007.

GOLDMAN, Alvin I. Knowledge in a Social World. Oxford: Oxford University Press, 1999.

GUASTINI, Riccardo. Interpretare e Argomentare. Milão: Giuffrè, 2011.

HAACK, Susan. Evidence and Inquiry. 2a. Ed. New York: Prometheus Books, 2009.

HAACK, Susan. Evidence Matters. Science, Proof, and the Truth in the Law. New York: Cambridge University Press, 2014.

HAACK, Susan. Manifesto of a Passionate Moderate. Chicago: University of Chicago Press, 1993.

HJELMSLEV, Louis. Prologomena to a Theory of Language. Trad. Fracis Whitfield. Londres: The University of Wiscosin Press, 1969.

LIMA, Renato Brasileiro de. Manual de Processo Penal. 8a . Ed. Salvador: JusPodivm, 2020.

LOPES JR., Aury. Direito Processual Penal. 17ª Ed. São Paulo: Saraiva Educação, 2020.

MORAES, Ana Luísa Zago de. Prova Penal: Da Semiótica À Importância Da Cadeia De Custódia. Revista Brasileira de Ciências Criminais. Vol. 132, p. 117-138, 2017.

MORRIS, Charles. Signification and Significance. A Study of the Relations of Signs and Values. Cambridge-Massachusetts, The MIT Press, 1964.

MUELLER, Christopher B.; KIRKPATRICK, Laird C. Evidence. 5a. ed. Frederick: Kluwer, 2012. 
NÖTH, Winfried. Handbook of Semiotics. Bloomington \& Indianapolis, 1990.

PAULA RAMOS, Vitor de. Respeite as Regras!. Revista da Faculdade de Direito Dom Alberto, v. 1, p. 40-57, 2013.

PEIRCE, Charles. Some Consequences of Four Incapacities. [1868]. In: HOUSER, Nathan; KLOESEL, Christian (orgs.). The Essencial Peirce. Vol. 1. Bloomington: Indiana University Press, 1992, pp. 28-55.

PEIRCE, Charles. Sign [1901]. In: HOOPES, James (org.). Peirce on Signs. Chapel Hill e Londres: The University of Carolina Pressa, 1991, p. 239-259.

PEIRCE, Charles. On the nature of Signs [1873]. In: HOOPES, James (org.). Peirce on Signs. Chapel Hill e Londres: The University of Carolina Pressa, 1991.

PRADO, Geraldo. Limite às Interceptações Telefônicas e a Jurisprudência do Superior Tribunal de Justiça. Rio de Janeiro: Lumen Juris, 2005.

PRADO, Geraldo. Prova Penal e Sistema de Controles Epistêmicos. A quebra da cadeia de custódia das provas obtidas por métodos ocultos. São Paulo: Marcial Pons, 2014.

PRADO, Geraldo. A cadeia de custódia da prova no processo penal. São Paulo: Marcial Pons, 2019.

SANTORO, Antonio E. R.; TAVARES, Natália L. F.; GOMES, Jefferson C. O protagonismo dos sistemas de tecnologia da informação na interceptação telefônica: a importância da cadeia de custódia. Revista Brasileira de Direito Processual Penal, Porto Alegre, vol. 3, n. 2, p. 605-632, mai./ago. 2017. https://doi.org/10.22197/ rbdpp.v3i2.76

SAUSSURE, Ferdinand de. Cours de Linguistique Générale. [1915]. 3a. ed. Payot: Paris, 1931.

SOUZA, Lia Andrade; VASCONCELLOS, Vinicius. A cadeia de custódia da prova obtida por meio de interceptações telefônicas e telemáticas: meios de proteção e consequências da violação. Revista Da Faculdade De Direito (UFPR), v. 65, p. 31-48, 2020. http://dx.doi.org/10.5380/rfdufpr.v65i2.68577

TARUFFO, Michele. La Prova nel Processo Civile. Milão: Giuffrè, 2012. 


\section{Informações adicionais e declarações dos autores (integridade científica)}

Agradecimentos (acknowledgement): Agradeço à Northwestern University e ao Prof. Dr. Ronald J. Allen, que me receberam no início de 2020 para pesquisa pós-doutoral. Agradeço, ainda, a Luis Felipe Kircher, pela atenta revisão do manuscrito, além dos(as) quatro avaliadores(as) da revista e da equipe editorial, pelas pertinentes e interessantes críticas, que muito contribuíram com o desenvolvimento do presente trabalho.

Declaração de conflito de interesses (conflict of interest declaration): o autor confirma que não há conflitos de interesse na realização das pesquisas expostas e na redação deste artigo.

Declaração de autoria e especificação das contribuições (declaration of authorship): todas e somente as pessoas que atendem os requisitos de autoria deste artigo estão listadas como autores; todos os coautores se responsabilizam integralmente por este trabalho em sua totalidade.

Declaração de ineditismo e originalidade (declaration of originality): o autor assegura que o texto aqui publicado somente foi depositado como postprint (https://doi.org/10.1590/SciELOPreprints.1565) e que futura republicação somente se realizará com a indicação expressa da referência desta publicação original; também atesta que não há plágio de terceiros ou autoplágio. 


\section{Dados do processo editorial}

(http://www.ibraspp.com.br/revista/index.php/RBDPP/about/editorialPolicies)

- Recebido em: 22/07/2020

- Controle preliminar e verificação de plágio: 15/08/2020

- Avaliação 1: 17/08/2020

- Avaliação 2: 18/08/2020

- Avaliação 3: 27/08/2020

- Avaliação 4: 30/08/2020

- Decisão editorial preliminar: 05/10/2020

- Retorno rodada de correções: $26 / 11 / 2020$

- Decisão editorial final: 02/12/2020

- Depósito postprint: 17/12/2020 (https://doi. org/10.1590/SciELOPreprints.1565)
Equipe editorial envolvida

- Editor-chefe: 1 (VGV)

- Editor-assistente: 1 (GNA)

- Revisores: 4

\section{COMO CITAR ESTE ARTIGO:}

RAMOS, Vitor P. Da Necessidade de Corroboração Probatória para a Reconstrução de Sentidos em Diálogos Obtidos por Interceptações Telefônicas. Revista Brasileira de Direito Processual Penal, Porto Alegre, vol. 7, n. 1, p. 537-566, jan./abr. 2021. https://doi.org/10.22197/rbdpp.v7i1.429

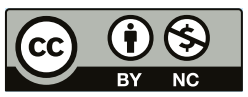

Esta obra está licenciada com uma Licença Creative Commons Atribuição-NãoComercial 4.0 Internacional. 